\title{
Methodology of interdisciplinary research on the example of scientific research of the human genome
}

\author{
$N$. Doronina ${ }^{1, *}, N$. Semilyutina ${ }^{1}$, and $M$. Tsirina ${ }^{1}$ \\ ${ }^{1}$ Institute of Legislation and Comparative Law under the Government of the Russian Federation, \\ Cheremushkinskaya str., 34, Moscow, 117218, Russia
}

\begin{abstract}
The problems of methodology of scientific research activity are actual to-day due to discoveries in Physics, Biology and Cosmology Due to widespread international cooperation and advances in the field of genomics (especially in sequence analysis), as well as major advances in computing technology, a «rough draft» of the genome was finished in 2000. This first available rough draft assembly of the genome was completed by the Genome Bioinformatics Group at the University of California. The OECD Project «Human Genome» is the first experience of application of methodology of scientific research activity based on mathematic modeling and cipher technology. The institutions, companies, and laboratories, engaged in OECD Human Genome Project, form a system based on laws and regulations, treaties and agreements, contracts and regulatory orders. This Model of methodological approach might have been used in other interdisciplinary scientific research activities. The study was carried out with the financial support of the Russian Foundation for Basic Research in the framework of research project No. 18-29-14025 on the topic: "Legal regulation of genomic research and the use of their results: comparative legal aspect of research».
\end{abstract}

\section{Introduction}

The relevance of the problem of the development of scientific research methodology is due to the fact that the humanities, in particular legal disciplines, remain far from the legal regulation of the use of the achievements of natural science research. Multidisciplinary research with a common approach to their legal regulation would help innovation advance in various areas of life. Currently, two approaches of research are equally to interesting. One of them is related to the differentiation of scientific disciplines: the infinite expansion of specialties, where each field of research is classified as an independent field of specialty. The solution of a scientific problem with this approach comes down to a search in the general system of legal regulation of scientific research for a small detail that's sufficiently modify or amend the law to solve a general problem.

${ }^{*}$ Corresponding author: gis.doronina@yandex.ru 
The improvement of legislation, in turn, is linked to the ever-increasing number of scientific specialties in law. [1] However, with this approach, the legal regulation of research remains systematic the rest of the process. [2] At the same time, the general approach to differentiating the methods of legal regulation in private and public legal relations retains its lasting value in law. It is this approach that is important in finding the right formula for the methodology of legal regulation of scientific research of the human genome. [3] Lawyers increasingly pay attention to such category in law as «value», which means «objects, phenomena and their properties that are necessary, useful to people and social groups of a particular society as a means of satisfying their needs and interests, as well as ideas and incentives as a norm, goal or ideal» [4]. The last makes us turn to ethical standards in determining limits in the research of the human genome.

The second approach is based on the division of science, taking into account the field of knowledge and the increasing importance of interdisciplinary research. When it comes to scientific research conducted in parallel in various fields of science, such as biology, physics and medicine, the adoption of legal norms should be very useful when it comes to research results in related disciplines and the possible legal consequences of using the results. It is important to anticipate at the beginning of planning research work and conducting scientific experiments which legal consequences will arise in case of making a discovery in the field of natural sciences. In the scientific research of the human genome the ban on conducting scientific experiments with the human genome was adopted at the international level. However, this an approach can also have various legal consequences that will ultimately endanger human life and health.

At first glance, The Human Fertilization and Embryology (Mitochondrial Donation) Regulations which was adopted in the UK in 2015, actually lifted the ban on conducting experimental research in the applicability of mitochondrial change technology. [5] The results of advanced research, and mainly the threat of an objective reality that 6,500 children are born annually in the UK with severe mitochondrial DNA damage, have forced to make amendments to existing acts. [6] The form itself of legislation concern to the certain types, and its content the regulations clearly define the limits of scientific research doesn't allow us to state that there is a change in the general principles of legal regulation of scientific research in the field of genetics that established in international law.

This example above allows to conclude that the adopted general approach to the legal regulation of multidisciplinary research at the level of interaction of legal systems (international and national, as well as private and public law (within the national legal system) allows us to provide innovative achievements in various fields science in order to improve human living conditions, and to eliminate the threat to human health simultaneously. Legal problems in connection with the development of science and technology arise, as a rule, in research activities at the intersection of sciences and in ensuring the protection of the rights of copyright holders when using (commercialization) the results obtained. [7]

\section{Materials and methods}

Methodology of the current research paper is consisting of proven general and special methods of scientific knowledge successfully tested in the course of fundamental and applied research:

1.Philosophical method based on dialectical method (of knowledge). This method belongs to the group of general methods.

2. The formal logic method, which includes analysis and synthesis, induction and deduction, abstraction and collation, analogy and comparison. This method belongs to the group of general methods. 
3. The systemic structural method. This method belongs to the group of general methods.

4. Historical method. This method belongs to the group of general methods.

5. The formal legal method of analysis. This method belongs to the group of legal research methods.

6. Dogmatic method (studying of legal dogma based on relevant laws). This method belongs to the group of special legal research methods.

7. Methods of interpretation of the law, which include lexical, systematic, teleological, doctrinal and authentic methods of interpretation. This method belongs to the group of special methods.

8. Contents analysis method. This method belongs to the group of expert and sociological methods of research and evaluation of received results.

The use of philosophical, formal-logical, systemic structural and historical methods was a requirement for the scientifically proven and methodically verified implementation of scientific research. It is impossible to conduct legal research without using the formal logic method, dogmatic method and method of interpretation of the law.

\section{Results}

The result of the application of the complex method of regulation of relations in the field of research activity has become research projects as a detached complex of normative regulation. In law, an integrated approach means various ways of combination private law and public law regulation methods of regulation. The legal regulation of interdisciplinary research is another matter.

The existence of two methods in the legal regulation of research activities requires the adoption of unified methodology for interdisciplinary research in natural sciences, including the human genome research. Based on a systematic approach to solving a particular problem, taking into account accepted research methods in any branch of science and legal regulation methods, it is possible to plan a scientific search and regulate individual experimental studies in the light of social needs and possible negative consequences. The law allows the creation of special structurally separate areas of joint legal regulation. [8]

Creating the basis for legal regulation of scientific research requires a deeper development of the methodology of interdisciplinary research. As practice shows, the methodology of legal regulation of interdisciplinary research is based on the interaction of theories in the humanities (for example, sociology and law, economics and law) and theoretical studies conducted at the intersection of the humanities and natural sciences (biology, physics, chemistry), for example, biology and law. At the intersection of the humanities and the natural sciences, new theories are created and that) explain the already well-known facts in a new way. So, for example, along with the development of research on the human genome, environmentalists (proponents of environmental protection) approach denies the possibility of presuming human's biological nature. In interdisciplinary scientific research, it is allowed to study the interaction of various theories.

\section{Discussion}

The theory of «rational» in the general theory of law allows to cover all branches of knowledge with a single research methodology. [9] Rationalism is an evaluation of judgments and actions in term of rationality, logic, prudence, expediency, efficiency, economy. The reference point of a scientific discussion about legal value in the light of new 
paradigms is the thesis that «post-non-classical scientific rationality» actualizes the appeal to a person as a subject of law, and, consequently, to the value component of his activity. [10] The question of methodology is to highlight what the value component of research activity is and when it is based on the widespread use of computer technology.[11]

«Digitalization», or the comprehensive entry of computer technology in any field of activity, is even more successfully transforms science into a productive force. The research of a person as a special type of activity, is aimed at the production of new knowledge. At the same time, it is necessary to take into account that, interacting with other forms of activity, the scientific field is constantly changing interacting with other forms of activity. «It testifies about the historical variation of the scientific activity itself». [12]

Interaction at the level of scientific theories provides ample opportunities, because scientific theory is a tool to predict the course of events occurring in reality. However, such a limited understanding of the role of scientific theory in solving a particular problem does not allow to determine which the path to cognition of reality should be. Besides, it seems important not only to formulate a scientific theory that predicts the course of reality, but also to plan experimental activities that confirm or disprove a particular theory or predictions put forward in accordance with the proposed scientific theory. All of this emphasizes the importance of developing a methodology for the legal regulation of research activities.

Scientific researches include two different types of activity: theoretical substantiation of reality and experimental confirmation of theoretical assumptions. For the legal regulation of natural science research, the distinction between the two types of scientific activity is particular important. It is important for determining a particular form of legal regulation of scientific research as a specific type of activity, taking into account the specifics the object of regulation. If the object of scientific research is clearly defined, the decision to carry out the corresponding work will largely depend on the choice of the method of research activity. The challenge lies in the fact that the subject of scientific research coincides with the object of study. Human, as an object of research, is a terra incognita as the cosmos, social community, and also the origin of life on earth are the same unexplored objects. In this case, special requirements may be submitted to the research methodology in the form of an experiment. The methodology for the interaction of scientific theories in the field of interdisciplinary research can play an important role.

The feature of the legal regulation of natural science research is that for them the main source of law is a law based on the principles of international law, which are is based on ethical rules. In the field of physics, there are the rules for preserving life on earth in international disarmament treaties, as well as the problems of war and peace solved in international law; in biology there are questions of removing the threat to human life. An example of a possible threat is a worldwide pandemic caused by an influenza virus, probably obtained by artificially. [13]

Ethical or moral rules, as the basis of the legislation of an individual state, is part of the philosophy of law and serves as the basis for the formulation of the norm on the permission to conduct any scientific research in any science. It defines the rules of human behavior who is an active participant in this activity. The appeal to philosophy, of which ethics is a part, is not accidental. Considering a person as a subject of scientific research in the field of genomic research, it turned out to be especially important to establish certain boundaries of human actions in this research, given that he is also an object of scientific research.

Currently, solution of such global problems as the appearance of life on planet Earth, possibly on other planets, the evolution and origin of living organisms on earth, the theory of the appearance of the Universe, etc., has become relevant. «Living in this vast world, where good and evil alternate, people, peering into the vast sky, asked themselves a lot of questions». [14] The answers to such questions could be given not by one special field of 
science, but by science as a whole. [15] Participation in the genomic research of specialists from various fields of science is a feature of this field of research and it should be taken into account when developing national legislation on scientific research activities in the study of the human genome.

National legislation should reflect the need for development of unified methodology for multidisciplinary research and determine the ways and prospects for its use. As early as the beginning of the 20th century, during the heyday of racial theories and national socialism in Germany, major philosophers noted: «Scientific fields are far removed from each other. The way they develop their items is radically different. Today, this disintegrated variety of disciplines is somehow held together only by the technical organization of universities and faculties and retains some significance only because of the practical purpose goal-setting of industries». [16]

Ethics is not a direct source of law, but it helps to eliminate doubts in setting the purpose of the research «We suppress our doubts and follow the majority, because we cannot imagine ourselves as pioneers propagating unknown difficult truths».[17] Ethics directs the experimental activities of scientists specializing in genomic research in biology.

For interdisciplinary research, such as research in experimental biology, research results can be achieved by referring to the science of all sciences - philosophy. «Each society has its own rules that determine what to believe in and how to behave so as not to be suspected and condemned. Sometimes such social convention receives strict wording in the code of laws, sometimes it is a collection of intuitive ethical and practical norms, called «common sense», which dictates what should be worn, how to manage finances, whom to respect, which etiquette rules to follow, how to organize your home life. Doubts in these findings seem strange, even unsafe». [18]

The above quote emphasizes the role of philosophy in the human's possession of the art of living. It is this quality that is required from scientific research of the human genome - in the name of human life, to eliminate the possibility of irreparable harm to humanity as a whole. In philosophy, we draw on the basic principles of legal regulation, which are enshrined in international legal documents. As for the legal regulation of specific relations presented in national legislation, it should take into account the features of scientific research as a specific type of human activity, in which a person is both an object and subject of scientific research.

\section{Conclusion}

The legal regulation of scientific research of the human genome takes are in the light into account of all the possibilities of specialization and cooperation of scientific research, not only in the natural sciences, but also in the cooperation of natural and humanitarian research. In law first of all attention should be paid to new models of cooperation of organizations of various functions involved in genomic research.

In the field of law, the specialization of certain legal entities is largely determined in accordance with the method of legal regulation: public-law or private-law regulation of the subject of relations arising from the implementation of a particular activity. When analyzing the national legislation of various states regarding scientific research of the human genome, attention is drawn that in the field of public law relations, state bodies exercise control over the practical activities of organizations involved in scientific research. In private law regulation, the subject matter is commercial contracts concluded in accordance with the free will of the participating parties. In the legal regulation of scientific research of the human genome, it is impossible to avoid the advantages that cooperation between organizations with various functions (control or entrepreneurship) provides. As a 
rule, such cooperation between business and government becomes punishable, at least by antitrust laws that monitors competition in the public interest.

As the results of genomic research show, the natural sciences have already developed their own methodology, which has the character of universal application, which can have an effective impact on the development of a methodology for the legal regulation of genomic research. «In the history of science, we observe a sequence of ever-improving theories, or models of the world: from Plato to Newton's classical theory to modern quantum theories». [18] In scientific studies of the human genome, as in quantum physics, the researcher has objects of observes objects that «do not even exist on their own, but exist only as part of an ensemble». [18]

Research in the field of natural sciences of lots of invisible objects (quanta, genome, electron and atom) due to the modeling of a certain world in which these objects exist. «We create models in science, but also create them in everyday life. Model-independent realism is applicable not only to scientific models, but also to conscious and subconscious mental models that we all create in order to interpret and understand everyday life». [18] In the field of observing invisible objects, built models of physical objects are the reality that becomes part of fundamental research. This is shown by modern British physicists $\mathrm{S}$. Hawking and L. Mlodinov, who proposed their universal M-theory of creation of the world. According to them, the significance of the theory of model-dependent realism can be demonstrated by the example of a model of the existence of a subatomic electron particle. «The electron was discovered in 1897 by the British physicist J.J. Thomson (1856 - 1940) from the Cavendish Laboratory at Cambridge University. He conducted experiments with electric current inside empty glass tubes - this phenomenon is known as cathode rays». Thomson's guess that the cathode rays he received were made up of tiny corpuscles was unambiguously confirmed by experience, although about electrons (material elements of atoms considered at that time) indivisible and were not known. Subsequently, the proposed model of the existence of electrons has shown «its indispensability in everyday use - from fundamental science, to engineering projects».

Accordingly, the so-called unified approach to the methodology of scientific research is has currently been) formed by constructing and analyzing mathematical models to predict the development of a particular phenomenon. This direction in research activity has a certain methodological feature. Mathematical modeling, or a unified scientific approach to research, ensures the effectiveness of scientific research in the field of both natural and human sciences.

The study was carried out with the financial support of the Russian Foundation for Basic Research in the framework of research project No. 18-29-14025 on the topic: "Legal regulation of genomic research and the use of their results: comparative legal aspect of research».

\section{References}

1. Scientific concepts for the development of Russian legislation (Edited by T.Ya. Khabrieva, Yu.A. Tikhomirova. Moscow: Jurisprudence, 2018)

2. N. Doronina, V.P. Emelyantsev, The development of legislation on science and high technology (Scientific concepts for the development of Russian legislation. Edited by T.Ya. Khabrieva, Yu.A. Tikhomirova. M.: Jurisprudence, 2018)

3. S.N. Bratus, The subject and method of civil law (Moscow: Jurizdat, 1960)

4. S.B. Polyakov, Legal and real principles of law, Journal of Russian Law 9, 20 (2018)

5. In the United Kingdom, the Human Fertilization and Embriology Act 1990 of 1990 continues to enforce the Prohibition of Germline Genetic modification. 
6. M. Nass, S. Nass, Mitochondrial DNA (Stockholm University, 1963)

7. N.G. Doronina, N.G. Semilyutina, Legal problems of electronic commerce in the international financial market, Journal of Foreign Legislation and Comparative Law (2019)

8. A.I. Abramova, Modern trends of integration and differentiation of legal regulation, Journal of Russian Law 9, 32 (2018)

9. V.S. Stepin, Philosophy of Science. Common problems (M. Gardarika, 2006)

10. V.S. Stepin, Theory of Culture, Selected lectures of St. Petersburg State Unitary university. 115, 50 (2010)

11. N. Doronina, N.G. Semilyutina, Legal Values in the Light of New Paradigms of the Development of Modern Civilization, the IX International Congress of Comparative Law «Legal Values in the Focus of Comparative Law», Institute of Legislation and Comparative Law under the Government of the Russian Federation (Moscow, 2019)

12. V.S. Stepin, Philosophy of Science. Common problems (M. Gardarika, 2006)

13. The consequences of a pandemic, even after the recovery of the last patient with COVID-19, will affect for many years (The Russian newspaper 04/27/2020)

14. S. Hawking, L. Mlodinov, Higher Design: Astrophysicist's View on the Creation of the World (Moscow: AST Publishing House, 2018)

15. P. Hogeweg, The roots of bioinformatics in theoretical biology, Public Library of Science for Computational Biology 7, 3 (2011) https://journals.plos.org/ploscompbiol/article?id=10.1371/journal.pcbi.1002021 (date of access: 02.09.2019).

16. M. Heidegger, Time and Being. Articles and speeches (St. Petersburg: «Science», 2007)

17. A. de Botton. The consolation of philosophy (Moscow: Eksmo, 2014)

18. S. Hawking, L. Mlodinov, Higher Design: Astrophysicist's View on the Creation of the World (Moscow: AST Publishing House, 2018)

19. P. Hogeweg, The roots of bioinformatics in theoretical biology, Public Library of Science for Computational Biology 7, 3 (2011)

20. U. Neel, J.N.L. Sukhatme, Cramer Who Cares About Patents? Cross-Industry Differences in the Marginal Value of Patent Term, American Law and Economics Review 21, 1 (2019)

21. A.I. Abramova, Modern trends of integration and differentiation of legal regulation, Journal of Russian Law 9 (2018)

22. M. Guzman, New ideas do not know borders, Russian Newspaper 80 (2019)

23. N.G. Doronina, V.P. Emelyantsev, The development of legislation on science and high technology (Scientific concepts for the development of Russian legislation, Moscow: Jurisprudence, 2018)

24. N.G. Doronina, N.G. Semilyutina, Legal problems of electronic commerce in the international financial market, Journal of Foreign Legislation and Comparative Law (2019)

25. Yu.N. Kashevarova, S.B. Balkhaev, F.V. Tsomartova, Law in the era of biotechnology: a collection of materials from the Student Conference (Moscow: Institute of Legislation and Comparative Law under the Government of the Russian Federation, 2018) 
26. T.Ya. Khabrieva V.V. Lazarev, A.Ya. Kapustin, Law and law in a programmed society (on the 100th anniversary of Daniel Bell): collection of scientific articles (M.: Institute of Legislation and Comparative Law under the Government of the Russian Federation, 2020) 